\title{
The State of Nutrition Education at US Medical Schools
}

\author{
Kelly M. Adams, ${ }^{1}$ W. Scott Butsch, ${ }^{2}$ and Martin Kohlmeier ${ }^{1,3}$ \\ ${ }^{1}$ Department of Nutrition, School of Medicine and Gillings School of Global Public Health, University of North Carolina at \\ Chapel Hill, 800 Eastowne Drive, Suite 100, Chapel Hill, NC 27514, USA \\ ${ }^{2}$ Harvard Medical School, Massachusetts General Hospital Weight Center, 50 Staniford Street, 4th Floor, Boston, MA 02114, USA \\ ${ }^{3}$ UNC Nutrition Research Institute, 500 Laureate Way, Kannapolis, NC 28081, USA
}

Correspondence should be addressed to Martin Kohlmeier; mkohlmeier@unc.edu

Received 27 October 2014; Revised 23 December 2014; Accepted 11 January 2015

Academic Editor: Eleni Kaldoudi

Copyright (C) 2015 Kelly M. Adams et al. This is an open access article distributed under the Creative Commons Attribution License, which permits unrestricted use, distribution, and reproduction in any medium, provided the original work is properly cited.

\begin{abstract}
Purpose. To assess the state of nutrition education at US medical schools and compare it with recommended instructional targets. Method. We surveyed all 133 US medical schools with a four-year curriculum about the extent and type of required nutrition education during the 2012/13 academic year. Results. Responses came from 121 institutions (91\% response rate). Most US medical schools $(86 / 121,71 \%)$ fail to provide the recommended minimum 25 hours of nutrition education; 43 (36\%) provide less than half that much. Nutrition instruction is still largely confined to preclinical courses, with an average of 14.3 hours occurring in this context. Less than half of all schools report teaching any nutrition in clinical practice; practice accounts for an average of only 4.7 hours overall. Seven of the 8 schools reporting at least 40 hours of nutrition instruction provided integrated courses together with clinical practice sessions. Conclusions. Many US medical schools still fail to prepare future physicians for everyday nutrition challenges in clinical practice. It cannot be a realistic expectation for physicians to effectively address obesity, diabetes, metabolic syndrome, hospital malnutrition, and many other conditions as long as they are not taught during medical school and residency training how to recognize and treat the nutritional root causes.
\end{abstract}

\section{Introduction}

Poor nutrition contributes to the development of most chronic diseases and even some acute conditions. The ongoing obesity epidemic demands urgent attention from physicians, and they can make a difference in their daily clinical practice without compromising the delivery of their usual services [1-3]. There is an increasing recognition that malnutrition is common in hospitalized patients, that it promotes the development of pressure ulcers and prolongs hospitalization stays, and that it is a major contributor to poor outcomes with many medical procedures. Timely nutritional assessment of at-risk patients and initiation of determined countermeasures are often effective and save costs [4]. Ill-advised overfeeding, on the other hand, can put malnourished patients at acute risk due to refeeding syndrome [5]. In fact, there are few areas of medical practice that are completely isolated from nutritional links or influences.
Physicians must be prepared for the many diverse situations when solid nutrition knowledge and clinical nutrition skills can improve the likelihood of optimal health outcomes. Physicians shape clinical practice patterns, direct other healthcare staff, and allocate resources. They must be able to recognize the importance of nutritional problems and take the initiative to make nutrition a key part of their daily practice, such as routinely including nutrition assessment during history-taking and physical examination. Physicians are the ones who routinely see patients when they need nutritional guidance the most; they must be able to recognize the need for a nutrition consultation, set the stage by explaining the importance of action to the patient, and then refer the patient to the appropriate professionals, such as a registered dietitian nutritionist.

Physicians in the US are largely on their own when it comes to learning how to look for signs of nutrition problems, how to explain the significance of nutrition-related conditions and appropriate interventions, and how to refer patients 
to nutrition professionals. The Association of American Medical Colleges (AAMC) has recently declined to incorporate nutrition into their new blueprint for medical competencies [6]. Furthermore, we have conducted three prior nutrition education surveys at four-year intervals since $2000[7,8]$ and consistently found that most medical schools do not even come close the recommendation of the National Research Council [9] to include at least 25-30 hours of nutrition education in the undergraduate medical curriculum.

The purpose of this study was to assess the state of nutrition education at US medical schools and compare it with recommended instructional targets. To this end, we conducted a nutrition education survey of the 2012/2013 academic year to examine the amount of and context for medical nutrition education in US medical schools. We also sought to compare the results with survey results from previous years.

\section{Methods}

As part of our work with the Nutrition in Medicine Project (NIM) at the University of North Carolina at Chapel Hill described elsewhere, we have well-developed contacts at nearly all US medical schools [10]. In most cases, this is the instructor who is actually providing nutrition education to medical students. Occasionally, it is a nutrition coordinator who oversees the nutrition content of the curriculum or an administrator with knowledge of the nutrition offerings. In all cases, we seek to identify the person with the most knowledge of the entire nutrition curriculum. We targeted US medical schools accredited by the Licensing Council for Medical Education (LCME) for inclusion in our survey if they had completed a full four-year cycle by the end of the 2012/13 academic year. The list of accredited US medical schools and their enrollment numbers was drawn from the tables published online by the AAMC [11]. Beginning in November 2012, we contacted by email the 133 schools fitting this criterion and asked them to complete an online survey to report the hours of nutrition education, the distribution across the four-year curriculum, and inclusion within specific disciplines, emphasizing the time period of the survey being the 2012/13 academic year. At schools where we did not have an established contact person, we asked the dean's office who was responsible for nutrition education at that school and sought to obtain a survey from him/her. We sent out periodic reminders with the option of responding to the questions by reply email through February 2014. Surveys that were submitted via email were entered into the web-based form by the authors. We made additional contacts by telephone, email, and in person until the response rate had exceeded our predetermined minimum response target of $86 \%$. Participation in our survey was voluntary. The Institutional Review Board at the University of North Carolina at Chapel Hill made the determination that this project was exempt from requiring ethical approval.

We retained the key questions that were in the previous quadrennial surveys by our project since 2000. The survey items included a core of questions used in identical form during the three previous survey campaigns for academic years
2000/2001, 2004/2005, and 2008/2009. In brief, the questions asked respondents to indicate the required nutrition instruction hours during the preclinical and clinical phases of the four-year medical school curriculum, specify the total nutrition instruction hours, and account for the location of these hours in specific instructional context (nutrition, physiology/pathology/pathophysiology, biochemistry, clinical practice sessions, integrated courses, and other contexts). We asked participants to identify the number of first-year medical students at their institutions and to indicate overall whether nutrition was required, optional, or not offered. We left these questions and the overall methodology unchanged since our initial survey to allow for comparisons over time. We also questioned respondents about their perceptions of the adequacy of nutrition instruction and asked whether they utilized the Nutrition in Medicine online curriculum. In performing our calculations, we specified zero hours of required nutrition instruction at any school which indicated only optional nutrition education. If a submitted survey used a range of hours (e.g., 20-25 hours), we used the midpoint of the range in our calculations (e.g., 22.5 hours). When respondents provided partial information, we performed simple calculations wherever possible, such as totaling the amount of nutrition education over four years. As we did in previous surveys, we placed no limits on what defines a "nutrition course" or what constitutes "nutrition education." Respondents themselves determined whether their schools provided nutrition in the various course categories.

We converted the dataset from the survey responses into a spreadsheet software program (Excel 2013; Microsoft Corp., Seattle, WA) to perform the calculations. We calculated means and standard deviations from the 2012/13 survey data and compared them to those from all previous survey years, using the same criteria and procedure. The statistical significance of contrasts was determined with Student's $t$-test for individual data pairs and with a Chi-square test for serial comparisons.

\section{Results}

During the 2012/13 academic year 141 US medical schools were fully or provisionally accredited by the LCME. Only information about the 133 schools with a fully operational four-year curriculum at the time of the survey is included in this report. A total of 121 (91\%) medical schools responded to the survey. Required questions pertained to the total amount of required nutrition across the four years, and thus all respondents completed this part of the survey. A vast majority of schools that required nutrition education answered the part of the survey asking where the required nutrition instruction occurs in the curriculum (103/109 or 95\%).

3.1. How Much Is Taught? The responding medical schools reported that they provide on average 19.0 hours of nutrition education with a standard deviation (SD) of 13.7 hours and a median of 17 hours. Over a third of the responding medical schools $(43 / 121,36 \%)$ reported requiring 12 or fewer hours of nutrition instruction; twelve of those institutions (9\%) 
TABLE 1: Nutrition instruction hours in various contexts at US medical schools that taught nutrition during the 2012/2013 academic year* .

\begin{tabular}{|c|c|c|c|c|c|}
\hline Course/context & Nutrition & Integrated & Biochemistry & Physiology & Clinical practice \\
\hline Number of schools & 22 & 82 & 45 & 35 & 55 \\
\hline $\begin{array}{l}\text { Number of hours of nutrition instruction } \\
\text { in this context, average (SD) }\end{array}$ & $13.8(7.3)$ & $12.6(10.4)$ & $6.4(6.0)$ & $4.2(3.2)$ & $6.4(6.6)$ \\
\hline $\begin{array}{l}\text { Total } 4 \text {-year nutrition curriculum hours } \\
\text { at schools using nutrition instruction in } \\
\text { this form, average (SD) }\end{array}$ & $22.2(8.6)$ & $22.1(13.7)$ & $21.7(11.4)$ & $23.1(11.7)$ & $24.2(14.8)$ \\
\hline $\begin{array}{l}\text { Percent of total instruction provided in } \\
\text { that course/context, average (SD) }\end{array}$ & $66.7(27.5)$ & $60.3(31.3)$ & $31.8(27.6)$ & $24.3(25.6)$ & $25.1(14.4)$ \\
\hline
\end{tabular}

${ }^{*} 121 / 133$ US medical schools responded to a survey that began in 2012. Most schools that provided nutrition education did so in more than one type of course or context. SD indicates standard deviation.

required none. Less than a third (35 of 121, 29\%) of the responding medical schools reported that they provide at least 25 hours of nutrition education across the four-year curriculum. In terms of enrollment, this means that $24.6 \%$ of all medical students get the minimum of 25 hours, while $16.1 \%$ of all US medical students (those enrolled at 24 schools) get 30 hours or more. Eight of these schools reported that they provide between 40 and 75 hours of nutrition education.

3.2. In What Context Is Nutrition Taught? Most reported nutrition education takes place during preclinical training, adding up to an average of 14.3 (SD 10.5) hours of instruction. The instructional hours of nutrition education are lower during clinical training with an average number of 4.7 (SD 6.2) required hours. This number of hours does not include various electives, seminars with voluntary attendance, or student-organized activities.

Table 1 shows in what specific kind of instructional setting medical students get their nutrition knowledge and practice skills. Most nutrition instruction occurs in the context of integrated courses or in stand-alone nutrition courses. At schools that teach nutrition in an integrated or dedicated nutrition course context, most of the nutrition instruction is provided in either one or the other context. Teaching nutrition as part of a basic science course or clinical practice session is usually only a smaller part of the total. Fewer than half of all responders (55/121, 45\%) reported any nutrition education defined as clinical practice. Respondents from 13 medical schools (11\%) reported that at least 10 hours of clinical nutrition practice activities were included in the curriculum. Shadowing of nutrition consults or mentored training of patient assessment and counseling were listed specifically by 3 of the surveyed medical schools (2\%).

Eighteen percent of schools (22 of 121) reported that their required curriculum includes a dedicated nutrition course (Table 1). We allowed respondents to self-determine what they considered a "nutrition course." At all but two schools who reported a nutrition course, this format provided at least 5 hours in total across the four-year curriculum.

Looking at the eight schools with 40 or more hours of total nutrition instruction, we found that none of them offer a dedicated nutrition course. In contrast, all but one of these schools provide substantial clinical practice components, accounting for 20.6 (SD 8.0, range 10-30) hours of their combined 56.4 hours of nutrition instruction.

3.3. The Impact of NIM Online Instruction. Respondents from a third (44/121) of all responding US medical schools indicated that they were actively using our NIM online instruction materials. These active users reported more nutrition instruction hours than the other schools (22.1 versus 17.4 hours, $P<0.04$ ). An additional 18/121 stated that the NIM materials were available to students as a resource. Overall, respondents from 32 schools reported that the availability of the NIM online modules helped to add nutrition instruction hours, 47 schools found that it improved the quality of nutrition education, and 37 indicated that it increased student awareness of nutrition.

3.4. Changes in the Amount and Delivery of Nutrition Instruction. Because our core questions and methodology remained unchanged since 2000, we were able to examine data from 113 medical schools for which total course hours were available in the current survey and also in at least one of our previous surveys. We found that there were 12 more schools with a reported decrease of required nutrition hours than schools with a reported increase $(P<0.05$, Chi-square test). The percentage of schools that did not meet the 25-hour nutrition instruction minimum recommendation was $71 \%$ (86/121); in our 2008 survey that percentage was $73 \%$ [8].

Table 2 shows that the number of medical schools with a required nutrition course declined progressively since the 2000 survey (Table 2). A correspondingly larger percentage of nutrition is now taught as a part of integrated courses. We had observed in our previous surveys $[7,8]$ that schools with dedicated nutrition instruction provided more nutrition instruction overall. This does not seem to be the case anymore. We now find very similar numbers of total nutrition instruction in schools teaching nutrition in the various modalities (Table 1). In particular, schools using integrated courses report total nutrition hours right in the middle of values among the different instructional contexts.

\section{Discussion}

4.1. Need for Better Nutrition Education. The quantity of nutrition education offerings in medical school curricula 
TABLE 2: Required nutrition education hours at US medical schools over time* .

\begin{tabular}{|c|c|c|c|c|}
\hline & 2000 & 2004 & 2008 & 2012 \\
\hline $\begin{array}{l}\text { Average hours of required nutrition } \\
\text { education }(\mathrm{SD})^{*}\end{array}$ & $20.4(13.6)$ & $22.3(15.3)$ & $19.5(13.5)$ & $19.0(13.7)$ \\
\hline $\begin{array}{l}\text { Median hours of required nutrition } \\
\text { education }\end{array}$ & 18 & 20 & 16 & 17 \\
\hline $\begin{array}{l}\text { Schools with a required nutrition course, } \\
\text { number/total (\%) }\end{array}$ & $39 / 112(35 \%)$ & $32 / 106(30 \%)$ & $26 / 105(25 \%)$ & $22 / 121(18 \%)$ \\
\hline Response rates, number/total (\%) & $100 / 112(89 \%)$ & $89 / 106(84 \%)$ & $90 / 105(86 \%)$ & $121 / 133(91 \%)$ \\
\hline
\end{tabular}

has shown no sign of improvement during the last decade, according to our surveys. Ever-expanding medical information and a growing set of needed clinical skills continue to fuel a fierce competition for curriculum time and attention of medical students. At the same time, fourth-year interviews for residency programs have compressed the curriculum to significantly less than the full four years. Our survey data suggest a steady erosion of nutrition education in medical schools, with median total nutrition instruction remaining at or under 20 hours since 2000. A few medical schools manage to exceed the recommended number of nutrition education hours and provide their students with a blend of integrated courses and clinical practice sessions, providing evidence that it can be done and giving a blueprint for ways other schools might increase their nutrition content. When we began our surveys in 2000, we were closely focused on whether or not a school had a designated, required nutrition course as one sign of successful implementation of a nutrition curriculum. Since that time, the face of medical education has changed dramatically, with didactic lectures being deemphasized while problem-based learning has gained ground. We fully expected respondents to attempt to quantify the nutrition portion of any independent research or group work related to any required activity, allowing us to continue to compare total nutrition content hours over time. Although the hours may be provided in a different manner than they were almost three decades ago, the material must still be mastered. Many medical schools have already or are in the process of transitioning to a fully integrated curriculum. We also expected our surveys to reflect the nutrition portion of any integrated activities, realizing that this required the respondent familiar with the curriculum to make some estimations.

It is important to emphasize that our surveys only counted required nutrition education. Many medical schools offer nutrition electives and other optional opportunities to engage in nutrition-related learning activities and practices. Students also often seek out instruction on their own initiative, particularly from the Internet. None of these very important activities are captured in our survey data. But it is always a small minority of students who have the initiative and take the extra time to use such opportunities [12]. Exceptional efforts and achievements of the motivated few will do little to ensure that all physicians are ready to serve the health needs of their patients.
It is hard to see how a medical school can fulfill its core mission and prepare future physicians with an average of just 19.0 hours of nutrition instruction. Experienced medical nutrition educators (the Curriculum Committee for the Nutrition Academic Awards) have put together a catalog of nutrition knowledge and skills that medical students need to master upon graduation [13]. Exactly what content needs to be mastered will always be subject to considerable debate and the efficiency of medical instruction will always vary. But even a cursory review of the 51 pages listing specific items across the full spectrum of typical clinical practice areas makes it obvious that this diverse and extensive content cannot be taught in a few hours. The 25-30 hours of required nutrition instruction recommended by the 1985 Report of the National Research Council's Committee on Nutrition in Medical Education [9] should be considered a minimum estimate, developed at a time when the scope of medically relevant nutrition knowledge was only a fraction of what it is today. In fact, in 1989, The American Society for Clinical Nutrition surveyed medical school curriculum administrators and medical nutrition educators separately about the number of hours and the scope of nutrition course work that medical schools should provide [14]. They found close agreement among these two groups (37 hours versus 44 hours, resp.). Considering the rapid advancement of nutrition knowledge and the understanding of the role of nutrition in disease prevention and treatment in the past 25 years, it seems likely that if these groups were surveyed again today, the minimum "benchmark" of 25 hours in our analysis would be much higher.

Significant gaps in medical nutrition instruction often remain unfilled due to a dearth of qualified instructors. The limited expertise of faculty without a background in nutrition has been identified as a significant barrier for teaching effective intervention techniques to the next generation of physicians [15]. A major reason for this lack of competent nutrition educators is the fact that only a handful of medical schools have full nutrition departments; less than a third of them have divisions or other academic units with at least a partial focus on nutrition. This means in practice that nutrition education is commonly delegated to faculty without professional training or other formal qualifications in nutrition, much less to faculty members who engage in nutrition practice and research on a regular basis. While many nonspecialist educators tasked with nutrition instruction 
have managed to build credible nutrition curricula, such outcomes are by no means ensured. Furthermore, earlier research has found that medical students and residents rarely have first-hand opportunity to observe and learn best nutrition practices from physicians with expertise in nutrition or from other licensed nutrition professionals $[16,17]$. The common absence of clinical nutrition role models for medical students is reflected in the limited time (6.4 hours on average) allotted to practice at the minority (55 out of 121) of schools that require any clinical nutrition practice sessions.

4.2. Impact on Physician Competence. Current medical nutrition education must still be considered inadequate at all levels of professional training [18-20], and this is evident in the published literature showing that many physicians do not feel confident in their clinical nutrition skills, particularly when it comes to dealing with overweight and obese patients [21]. The few pieces of available objective data on clinical nutrition competencies of recently graduated physicians indicate that medical schools do not prepare their students adequately for the typical challenges of everyday practice. One survey of medical residents in a highly rated and competitive program found that only a small minority (14\%) felt prepared to provide competent nutrition guidance to their patients [22]. A detailed knowledge test demonstrated that the bleak selfassessment of these residents was well founded. There is no indication that ill-prepared medical school graduates usually make up for deficits in their medical school education later on through extensive additional nutrition instruction and skill building opportunities $[23,24]$.

A review of patient records indicated that fewer than $10 \%$ of primary care providers (PCPs) in the US provide weightloss counseling to their patients [25]. It is not because over $90 \%$ of PCPs think that such counseling is unimportant. A recent survey indicated that most primary practice physicians want to be better prepared for obesity care and overwhelmingly call for additional training in nutrition counseling and other effective interventions [26]. There are certainly many obstacles that prevent implementing proper weight assessment and interventions into busy practices. We have to assume that a lack of nutritional knowledge, engrained assessment procedures, and counseling skills contribute significantly to existing barriers.

4.3. What Can Be Done to Improve Nutrition Education? The eight medical schools with $40-75$ hours of nutrition education are noteworthy because they demonstrate that medical school curricula can accommodate extensive coverage. These medical schools prepare their students for clinical practice by integrating nutrition content into preclinical subjects ( 25 hours on average). Most of them are then following up with extensive nutrition activities during their various clinical rotations (24 hours on average). This approach avoids the addition of even more hours to an already overcrowded curriculum. At the same time, it offers considerable advantages by addressing nutrition assessment and interventions in the context of organ- and disease-related instruction and typical clinical practice. Reviews of nutrition-related disease processes do not have to be duplicated, and various modes of disease prevention and treatment can be put into proper perspective, for example, by comparing efficacy and outcome expected with nutrition interventions to medication or surgical interventions and discussing how different modalities may be combined. It is obvious that meshing nutrition content with other clinical instructions requires strong nutrition education leadership and careful planning if the nutrition component of the integrated course is not to be a facile label without substance. Spreading instruction across the full curriculum also helps students to build on their preclinical instruction and connect nutrition theory to actual case management during their clinical rotations. Unfortunately, there are only few medical schools where all students are required to learn how to interview and counsel patients about their nutrition options in a mentored setting [27]. Students at a significant number of medical schools have responded to the perceived lack of nutrition instruction by organizing supplemental offerings on their own [28]. The Nutrition in Medicine (NIM) project is frequently contacted directly by such medical students about the availability of our online materials, and in a number of instances we were able to coordinate with school administrators and help them get nutrition instruction started.

4.4. Strengths. A major strength of our survey is the high response rate (91\%), which gives us confidence that we have captured the current state of nutrition education across the entire country and not just in a specific region or type of medical school. Particular strengths of the survey are the use of our consistent methodology and identical questions since 2000 , allowing us to compare 4 time points over 12 years. Our previous quadrennial surveys had similarly high response rates of $84-89 \%$. Our survey instrument asks the respondent to specify the total hours of required nutrition education over the 4 years of medical school, as well as to indicate the number of hours in each specific course or curriculum type. Phrasing the same questions two different ways should prompt careful consideration on the part of the respondent and allowed us a chance to ask for clarification when the reported totals did not match. Our survey methodology targets the many instructors with whom we have developed relationships over the years, so we are confident that they are knowledgeable about the nutrition teaching they report.

4.5. Limitations. We acknowledge the inherent difficulty in characterizing something as complex and wide-ranging as nutrition instruction across a four-year curriculum. We realize that we are asking respondents to quantify something that may be more easily described in narrative form; however, a full curriculum review at all medical schools is not feasible with currently available resources. We are dependent on the reliability of our respondents, who may not always be fully informed of current curriculum scope and formats; however, as mentioned previously, we have long-standing relationships with many of our respondents and we have taken great pains to ensure that we are surveying the person most knowledgeable about the nutrition offerings at that school. We have always left the interpretation of what constitutes "nutrition education" to the individual respondent, so it 
is possible that there are varying interpretations from one respondent to the next. Finally, we recognize that the raw number of curriculum hours does not necessarily predict the sufficiency of nutrition education across the medical school curriculum. We know that many instructors outside the dedicated nutrition courses are self-taught in the area of nutrition and do not have a strong background in clinical nutrition service or nutrition research. It is possible that a school might report a large number of hours, but the quality of education is lacking. On the other hand, it is unlikely that a school with a low number of required nutrition education hours is adequately covering the nutrition knowledge and skills that are needed. This makes it possible that the state of nutrition education at many medical schools may be even worse than the already inadequate number of curriculum hours suggest.

\section{Conclusions}

Many US medical schools still fail to prepare future physicians for everyday nutrition challenges in clinical practice. Nutrition is a dominant contributor to most chronic diseases and a key determinant of poor treatment outcomes. It cannot be a realistic expectation for physicians to effectively address obesity, diabetes, metabolic syndrome, hospital malnutrition, and many other conditions as long as they are not taught during medical school how to recognize and treat the nutritional root causes.

A few medical schools demonstrate that an alternative model with extensive nutrition education is compatible with the constraints of a crowded four-year medical curriculum. What we urgently need is the will to weave nutrition content credibly into other basic science and clinical topics, to offer such integrated learning sessions from the beginning to the end of undergraduate medical education and beyond, and to add a generous dose of nutrition practice opportunities. Instructors, curriculum committees, and medical school administrators need to be held accountable by licensing boards, and ultimately the general public, to meet generally recognized instructional standards. It is unacceptable that we keep finding the same systemic instructional failures decade after decade and still just hope for the best. What counts in the end is the readiness and ability of physicians to recognize and effectively address nutrition-related challenges in their patients. The reported educational deficits of medical school curricula go a long way to explain why many physicians miss opportunities to use nutrition as an effective healthcare tool.

\section{Ethical Approval}

The Institutional Review Board of the University of North Carolina at Chapel Hill made the determination that this project was exempt.

\section{Conflict of Interests}

The authors declare that there is no conflict of interests regarding the publication of this paper.

\section{Acknowledgments}

The authors thank all the medical school faculty members who completed surveys and provided many helpful comments. The Nutrition in Medicine project was supported in part by Grants R25CA65474 and R25CA134285 from the National Cancer Institute, by Grant DK56350 for the UNC Clinical Nutrition Research Unit and by funds from the UNC Nutrition Research Institute.

\section{References}

[1] J. G. Thundiyil, D. Christiano-Smith, S. Greenberger, K. Cramm, J. Latimer-Pierson, and R. F. Modica, "Trimming the fat: identification of risk factors associated with obesity in a pediatric emergency department," Pediatric Emergency Care, vol. 26, no. 10, pp. 709-715, 2010.

[2] K. A. Shaw, A. B. Caughey, and A. B. Edelman, "Obesity epidemic: how to make a difference in a busy OB/GYN practice," Obstetrical \& Gynecological Survey, vol. 67, no. 6, pp. 365-373, 2012.

[3] M. R. Jay, C. C. Gillespie, S. L. Schlair et al., "The impact of primary care resident physician training on patient weight loss at 12 months," Obesity, vol. 21, no. 1, pp. 45-50, 2013.

[4] A. Vivanti, E. Isenring, S. Baumann et al., "Emergency department malnutrition screening and support model improves outcomes in a pilot randomised controlled trial," Emergency Medicine Journal, 2013.

[5] J. A. Palesty and S. J. Dudrick, "Cachexia, malnutrition, the refeeding syndrome, and lessons from Goldilocks," Surgical Clinics of North America, vol. 91, no. 3, pp. 653-673, 2011.

[6] R. Englander, T. Cameron, A. J. Ballard, J. Dodge, J. Bull, and C. A. Aschenbrener, "Toward a common taxonomy of competency domains for the health professions and competencies for physicians," Academic Medicine, vol. 88, no. 8, pp. 1088-1094, 2013.

[7] K. M. Adams, K. C. Lindell, M. Kohlmeier, and S. H. Zeisel, "Status of nutrition education in medical schools," American Journal of Clinical Nutrition, vol. 83, no. 4, pp. 941S-944S, 2006.

[8] K. M. Adams, M. Kohlmeier, and S. H. Zeisel, "Nutrition education in U.S. medical schools: latest update of a national survey," Academic Medicine, vol. 85, no. 9, pp. 1537-1542, 2010.

[9] Committee on Nutrition in Medical Education FaNB, Commission on Life Sciences, and National Research Council, Nutrition Education in U.S. Medical Schools, The National Academies Press, Washington, DC, USA, 1985.

[10] K. M. Adams, M. Kohlmeier, M. Powell, and S. H. Zeisel, "Invited Review: Nutrition in medicine: nutrition education for medical students and residents," Nutrition in Clinical Practice, vol. 25, no. 5, pp. 471-480, 2010.

[11] Total Enrollment by U.S. Medical School and Sex, 2009-2013 (table 26), Association of American Medical Colleges Web site, 2012, https://www.aamc.org/data/facts/enrollmentgraduate/ 158808/total-enrollment-by-medical-school-by-sex.html.

[12] R. L. Weinsier, J. R. Boker, E. B. Feldman, M. S. Read, and C. M. Brooks, "Nutrition knowledge of senior medical students: a collaborative study of southeastern medical schools," American Journal of Clinical Nutrition, vol. 43, no. 6, pp. 959-968, 1986.

[13] Curriculum Committee of the Nutrition Academic Award Program, Nutrition Curriculum Guide for Training Physicians, 2002, http://www.nhlbi.nih.gov/research/training/naa/products/curr gde/index.htm. 
[14] R. L. Weinsier, J. R. Boker, C. M. Brooks et al., "Priorities for nutrition content in a medical school curriculum: a national consensus of medical educators," American Journal of Clinical Nutrition, vol. 50, no. 4, pp. 707-712, 1989.

[15] S. L. Goff, E. S. Holmboe, and L. Curry, "Barriers to obesity training for pediatric residents: a qualitative exploration of residency director perspectives," Teaching and Learning in Medicine, vol. 18, no. 4, pp. 348-355, 2006.

[16] R. L. Weinsier, J. R. Boker, C. M. Brooks et al., "Nutrition training in graduate medical (residency) education: a survey of selected training programs," American Journal of Clinical Nutrition, vol. 54, no. 6, pp. 957-962, 1991.

[17] D. Deen, E. Spencer, and K. Kolasa, "Nutrition education in family practice residency programs," Family Medicine, vol. 35, no. 2, pp. 105-111, 2003.

[18] R. A. Dimaria-Ghalili, M. Edwards, G. Friedman et al., "Capacity building in nutrition science: revisiting the curricula for medical professionals," Annals of the New York Academy of Sciences, vol. 1306, no. 1, pp. 21-40, 2013.

[19] R. F. Kushner, L. Van Horn, C. L. Rock et al., "Nutrition education in medical school: a time of opportunity," The American Journal of Clinical Nutrition, vol. 99, no. 5, supplement, pp. 1167S-1173S, 2014.

[20] C. M. Lenders, D. D. Deen, B. Bistrian et al., "Residency and specialties training in nutrition: a call for action," American Journal of Clinical Nutrition, vol. 99, no. 5, pp. 1174S-1183S, 2014.

[21] M. Jay, C. Gillespie, T. Ark et al., "Do internists, pediatricians, and psychiatrists feel competent in obesity care? Using a needs assessment to drive curriculum design," Journal of General Internal Medicine, vol. 23, no. 7, pp. 1066-1070, 2008.

[22] M. L. Vetter, S. J. Herring, M. Sood, N. R. Shah, and A. L. Kalet, "What do resident physicians know about nutrition? An evaluation of attitudes, self-perceived proficiency and knowledge," Journal of the American College of Nutrition, vol. 27, no. 2, pp. 287-298, 2008.

[23] M. Raman, C. Violato, and S. Coderre, "How much do gastroenterology fellows know about nutrition?" Journal of Clinical Gastroenterology, vol. 43, no. 6, pp. 559-564, 2009.

[24] J. S. Scolapio, A. L. Buchman, and M. Floch, "Education of gastroenterology trainees: first annual fellows' nutrition course," Journal of Clinical Gastroenterology, vol. 42, no. 2, pp. 122-127, 2008.

[25] J. L. Kraschnewski, C. N. Sciamanna, K. I. Pollak, H. L. Stuckey, and N. E. Sherwood, "The epidemiology of weight counseling for adults in the United States: a case of positive deviance," International Journal of Obesity, vol. 37, no. 5, pp. 751-753, 2013.

[26] S. N. Bleich, W. L. Bennett, K. A. Gudzune, and L. A. Cooper, "National survey of US primary care physicians' perspectives about causes of obesity and solutions to improve care," $B M J$ Open, vol. 2, no. 6, Article ID e001871, 2012.

[27] Nutrition in the Medical School Curriculum: What and Where Nutrition Topics are Taught by NAA Faculty, Nutrition Academic Awards Program, National Institute of Heart, Blood, and Lung Disease, 2013, http://www.nhlbi.nih.gov/funding/ training/naa/products.htm.

[28] N. Agrawal, S. A. Ostrosky, and D. Henzi, "The introduction of nutrition education into the medical school curriculum: using an elective course to teach students the fundamentals, the science, and the clinical implications of food," Medical Science Educator, vol. 23, no. 2, pp. 225-232, 2013. 

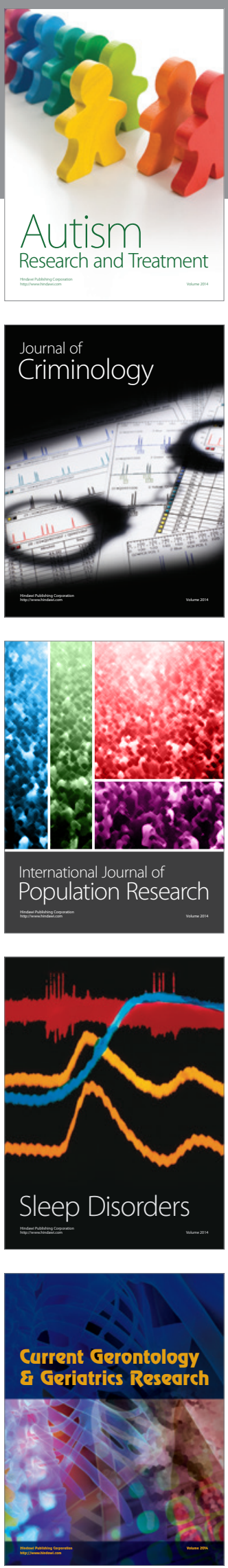
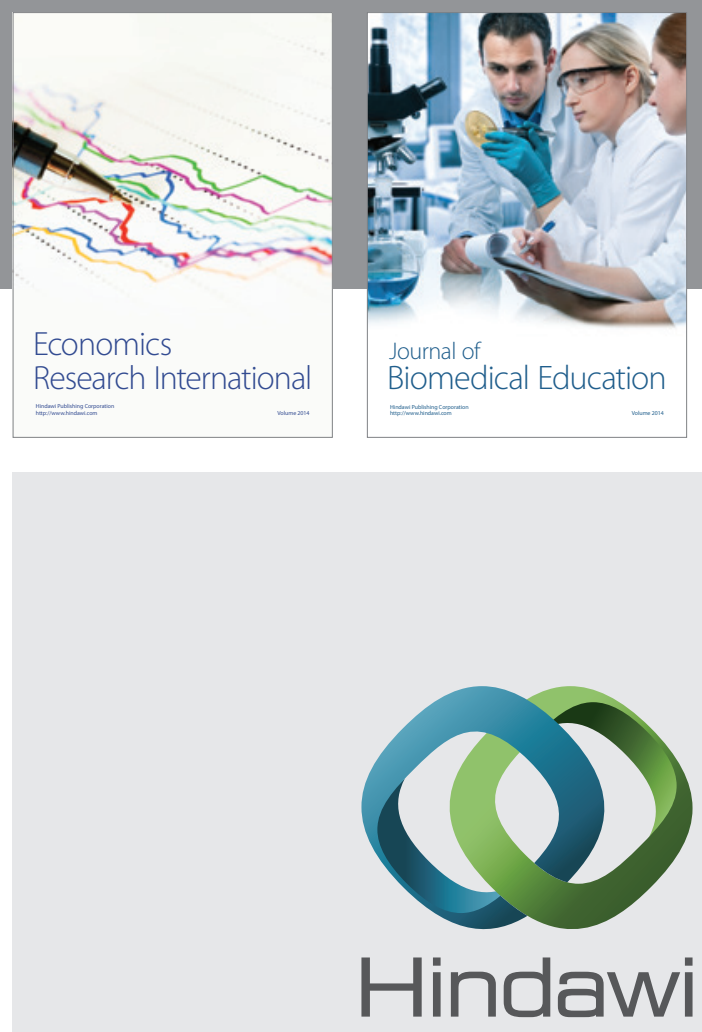

Submit your manuscripts at

http://www.hindawi.com
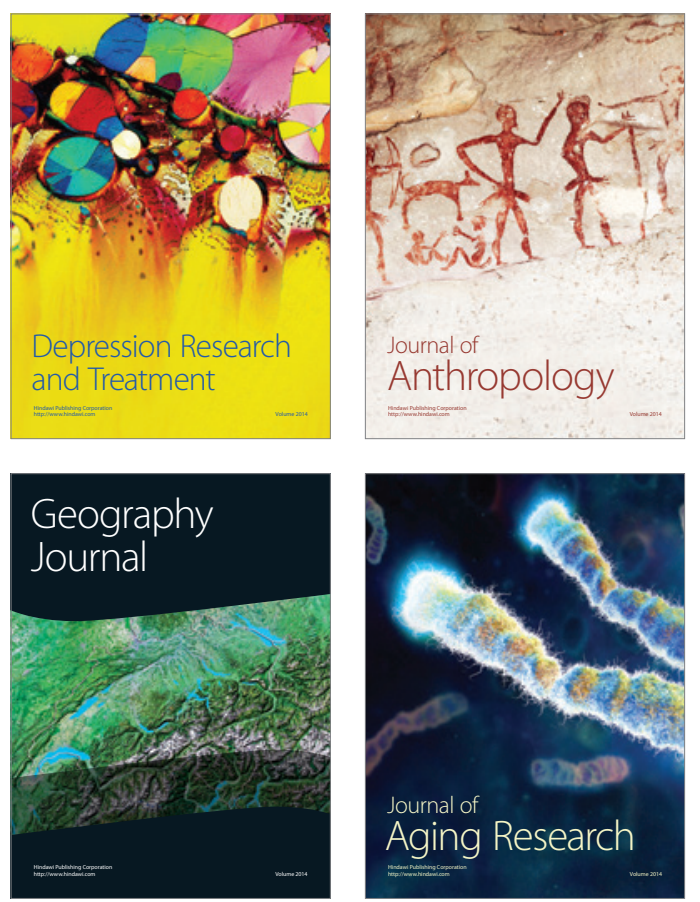
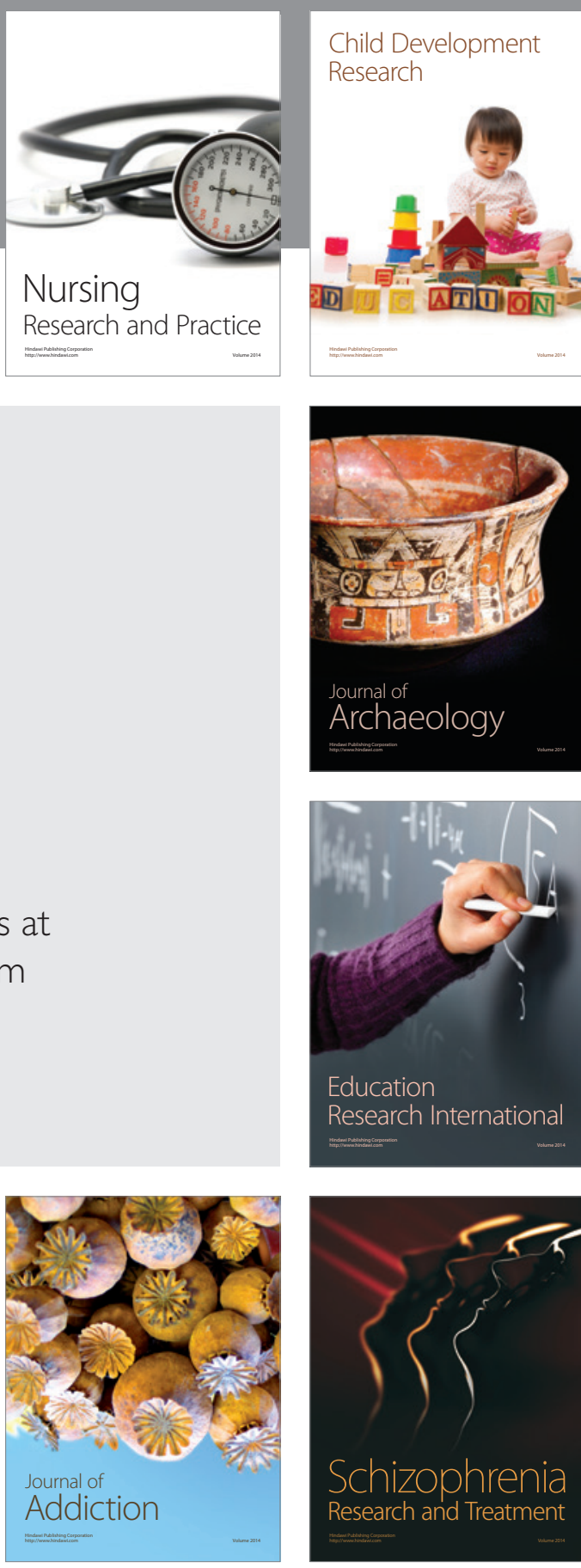

(D)
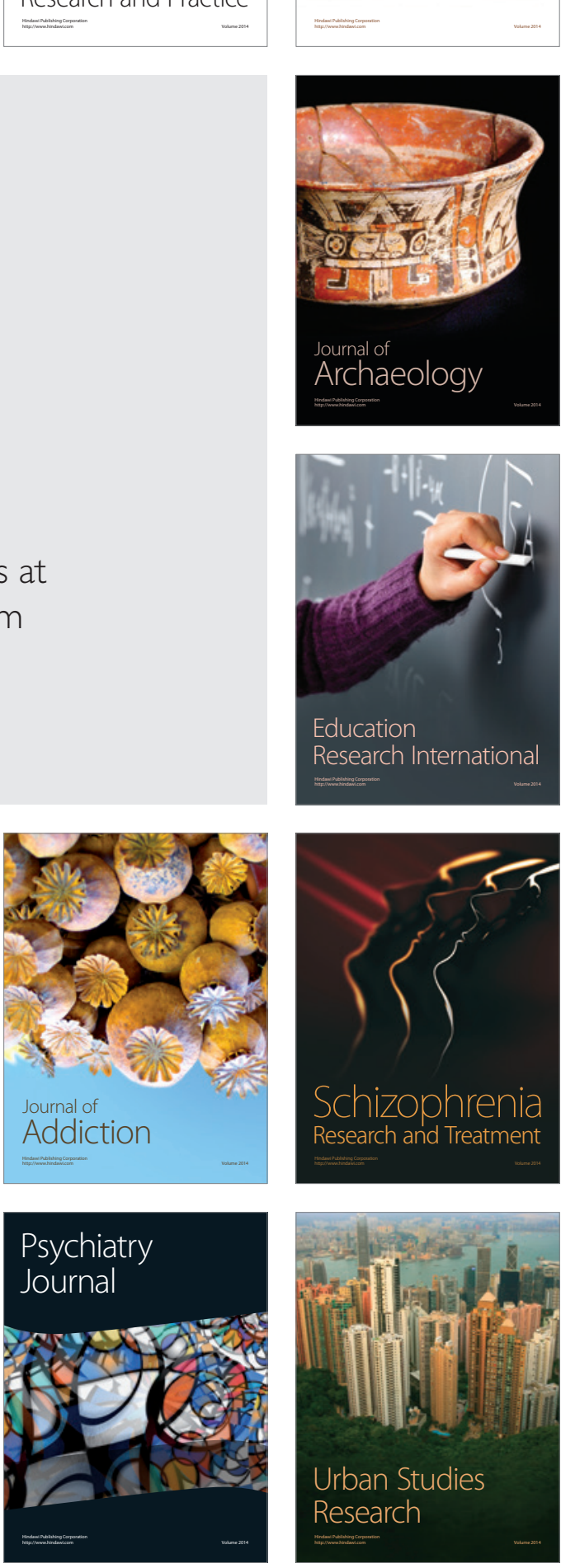